\title{
An Insight into a School's Readiness to Implement a CAPS Related Indigenous Knowledge Curriculum for Meteorological Sciences
}

\author{
Alvin Daniel Riffel \\ Department of Education, University of the Western Cape, South Africa
}

Copyright (C) 2015 by authors, all rights reserved. Authors agree that this article remains permanently open access under the terms of the Creative Commons Attribution License 4.0 International License

\begin{abstract}
This paper looks at those aspects of Indigenous Knowledge (IK) that are socially and culturally relevant in South Africa for teaching meteorological science concepts in a grade 9 geography class room using dialogical argumentation as an instructional model (DAIM). Focusing on the Western Cape Province, and using a quasi-experimental research design model, the study employed both quantitative and qualitative (mixed methods) to collect data in a public secondary school in Cape Town, in the Western Cape Province. The study employed a dialogical instructional model (DAIM) with an experimental group of learners exposed to the DAIM intervention, and recorded differences like: responses to the DAIM method of teaching/learning; learner performance (scores in the post MLT test); depth of learners' understanding about weather/meteorological concepts; their perceptions/ attitudes towards Geography - between this group and a control group which had no intervention. Learners from the two groups were exposed to a meteorological literacy test (MLT) evaluation before and after the DAIM intervention. The results from the two groups were then compared and analysed according to the two theoretical frameworks that underpin the study namely: Toulmin's Argumentation Pattern - TAP [46] and Contiguity Argumentation Theory CAT [23].
\end{abstract}

Keywords Indigenous Knowledge Systems, Weather Prediction, Dialogical Argumentation, Cognitive Harmonization

\section{Introduction}

The main issue surrounding the implementation of Curriculum Assessment Policy Statement (CAPS) [5] has been the inclusion of IKS into the main school science curriculum. Some of the rationales cited for the inclusion of IKS were:

- There is 'lost knowledge' within IKS that needs to be rediscovered and recovered $[15,18]$.
- "People tend to use different ways of thinking for different situations, and even scientists in their daily lives may have religious frameworks or other ways of giving value to life and making choices..." [6] and that:

... One can assume that learners in Natural Sciences Learning Area think in terms of more than one world-view. Several times a week they cross from the culture of home, over the border into the culture of science, and then back again [6,23].

The current Minister of Basic Education; Angie Motshekga [5] in her foreword to the Curriculum and Assessment Statement (CAPS) argues that despite its limitations the new curriculum is more relevant to learners in a diverse and multicultural society as South Africa than the apartheid curriculum. Further, she justifies the various revisions that the curriculum has undergone since its inception in 1997 based on experience and the need for transformation of the South African society. According to her:

Our national curriculum is the culmination of our efforts over a period of seventeen years to transform the curriculum bequeathed to us by apartheid. From the start of democracy, we have built our curriculum on the values that inspired our Constitution (Act 108 of 1996)...In 1997, we introduced outcomes-based education to overcome the curricular divisions of the past, but the experience of implementation prompted a review in 2000. This led to the first curricular revision: the Revised National Curriculum Statement Grades R-9 and the National Curriculum Statement Grades 10-12 in 2002. Ongoing implementation challenges resulted in another review in 2009...From 2012 the two National Curriculum Statements, for Grades R-9 and Grades 10-12 respectively, are combined in a single document and will simply be known as the National Curriculum Statement R-12. The National Curriculum Statement for Grades $R-12$ builds on the previous curriculum but also updates it and aims to provide clearer specification of what is to be taught 
and learnt on a term-by-term basis (Motshekga, 2011: forward page).

My reasons for focusing on indigenous knowledge systems (IKS) in this study were twofold: the latest Curriculum Assessment Policy Statement (CAPS) [5] document for Natural Science from the Department of Basic Education indicates a change in the curriculum plan which incorporates "indigenous knowledge", which was effective from January 2011. I was also concerned about the vague explanation provided at the time by the Department of Basic Education concerning plans to follow and sketchy indications of assessment strategies to be employed by teachers in using IKS in the classroom in Specific Outcome 3.2 of the Natural Sciences Learning Area:

\subsection{Relationship of Indigenous Knowledge to Natural Sciences}

\section{Examples that are selected (and that should, as far as possible, reflect different South African cultural groupings) will also link directly to specific areas in the Natural Sciences subject content. [5]}

In this paper I argue that implementing aims such as this is likely to have, and has already had, direct implications for the Natural Science curriculum in the majority of South African schools, which do not have the space, framework or resources to develop IKS properly, or in adequate fulfillment of such Specific Outcomes as the one quoted above. In this context the introduction of IKS into various Learning Areas in the National Curriculum has opened up a debate amongst IKS-researchers, curriculum developers, academics and education specialists, based on the premise that IKS is an integral part of any culture or society and cannot be ignored simply in the interests of creating a smoother assessment curriculum policy statement [39].

I would argue that IKS forms the basis of every learning area, whether Natural Science, Life and Living Skills, or Social Sciences, and should be regarded at school level by education researchers, policy makers and practitioners as a point of departure for learning and for both acquiring and creating new knowledge (according to the Constructivist perspective underpinning the curriculum), as well as generating healthy argumentation in the classroom and amongst learners of all ages.

\section{Background of Study}

This study investigates the perceptions of high school learners' in their particular social context as well as their cultural beliefs about, and their attitudes towards, indigenous knowledge systems (IKS), and the relationship of these systems to meteorological knowledge and education, including weather predictions and their cultural-religious associations and values. This study also focuses on the perceptions of high school learners and the views that they hold concerning cultural knowledge, world/Western scientific knowledge and the Nature of Science (NOS) in relation to meteorological concepts. A further aim of this study is to investigate and establish the nature and extent and the kinds of views high school learners' have of indigenous knowledge systems as constituting and informing instruction in the classroom. The authors of the newly drafted CAPS (2011) document from the Department of Basic Education in South Africa have included IKS in the curriculum and in the assessment policies and practices as one of the ways of enhancing learners' understanding of the Nature of Science (NOS) and developing their ability to make a positive connection with those aspects of cultural knowledge that support IKS.

\section{Problem Statement}

Both the Revised National Curriculum Statement (RNCS) [6] and the Curriculum and Assessment Policy Statement (CAPS) [5] suggest the need to relate knowledge in the Natural and Social Sciences to IK as a way of closing the gap between the knowledge learners acquire and develop at home and what they learn at school, as well as a way to develop a holistic understanding of their bio-physical and socio-cultural environment. In this regard the expectations inscribed in the Revised Curriculum Statement and the CAPS (under 'Critical Outcomes') are for learners to be able to develop certain process skills that they need to solve the problems they encounter in their daily lives. These process skills call for the mobilization of critical thinking skills in classroom discourse [32]. However this presupposes that learners have the freedom and the opportunity for self-expression and for questioning in the classroom. This form of classroom interaction where learners are able to express their views without feeling intimidated or lacking in knowledge comes under the general umbrella of 'argumentation instruction', a teaching and learning approach that has been receiving increasing attention in both local and international literature since the beginning of the $21^{\text {st }}$ century. In a study Stears and Malcolm [36] conducted in the Cape Flats region of the Western Cape, South Africa they found that "relevance and participation go together: relevance encourages learners to participate in classroom processes more deeply, learning in their own ways and bringing together ideas, interests and experiences" [36]. Stears and Malcolm [36] refer to previous studies which have identified a number of dimensions of relevance. In studies done in Australia Linkson [15] make a plea for cultural appropriateness, and Fleer [10] for inclusion of multiple worldviews and social and political aspects of science. Peacock [27] and Terwel [37] advocate for linking classroom knowledge to children's everyday experiences, and Goodenough [12] for accommodation of multiple intelligences and learning styles [36].

\section{Dialogical Argumentation}

Argumentation is a form of conversation involving two people or members of a group with the sole purpose of reaching some consensus. In a classroom context argumentation instruction is a method of teaching and 
learning in the course of which the teacher creates opportunities in class for learners to argue about and discuss freely a particular topic in a situation where learners possess a variety of viewpoints or worldviews [22]. Meteorological concepts in theory provide ample opportunities for learners to argue from various scientific, religious or cultural perspectives. For example, learners from various cultural groups may hold different views, or carry cultural 'myths' or subscribe to a cosmology concerning the causes of natural phenomena (e.g. lightning, thunder, changes in the seasons, floods, or cold fronts as a major source of rainfall, etc.)

As a way of pointing a way forward for achieving the outcomes of the new curriculum, the study adopted the dialogical argumentation method of teaching and learning as an intervention in one Geography classroom. Numerous studies $[1,3,9,13,29,36]$ have demonstrated the value and effectiveness of dialogic argumentation as an instrument for discovering teachers' and learners' conceptual understandings, as well as making them aware of the tentative and material-discursive nature of the natural sciences [19]. According to this argument, the use of dialogical argumentation in the Geography and/or Social or Natural Sciences class room should help teachers and learners in other learning areas to understand the processes involved in 'border crossing' into the cultural spaces of hidden indigenous knowledge [21]. This process, I would argue, not only allows the teacher the time to build on both school and every day/home knowledge of learners, but to become acquainted with, and rediscover, the indigenous knowledge that has been lost to many in indigenous communities or cultures due to urbanization and to the pervading impact of 'school science' based on Western science and empirical knowledge.

\section{Purpose of the Study}

The main aim of the present study is to investigate what kind of IK in South Africa, in the Western Cape specifically, is socially and culturally relevant in teaching meteorological science concepts to a group of Grade 9 learners in a specific socio-economic and cultural context using a dialogical argumentation-based instructional model (DIAM) in a CAPS related classroom.

In the course of the study emphasis is placed on how this group of learners relate socially and culturally to selected meteorological concepts and how they interpret them within the context of the current school curriculum, CAPS. The study also aims to create awareness among these learners, and their teachers, about the importance of certain weather concepts, and their interpretation of such concepts.

In particular, the study focused on the following questions:

What indigenous knowledge system (IKS) concepts do Grade 9 learners currently hold?

What are Grade 9 learners' ideas about, and attitudes towards, integrating indigenous knowledge (IKS) with school/Western meteorological science?
What are the effects of dialogical argumentation instruction on Grade 9 learners' indigenous knowledge (IK) conceptions, understandings, and attitudes towards Geography?

\section{Literature Review}

The literature review focuses on theoretical and practical issues regarding grade 9 learners' conceptions and understandings of selected meteorological concepts. In this context theoretical issues are those theory related issues raised in the literature and based on the views expressed by recognized scholars in the area, while the practical issues deal with actual studies done in the area. This study investigates grade 9 high school learners' understandings (social and cultural) of meteorological concepts and phenomena. Such conceptions include, or subsume, both (Western) scientifically valid ideas and what is understood in this study as indigenous knowledge systems (IKS) regarding a group of learners' conceptions about weather conditions/phenomena and/or environmental factors.

According to Ogunniyi and Hewson [19], dialogical argumentation occurs when different perspectives of a subject are expressed by opposing groups or individuals with the hope of their ultimately reaching consensus. The purpose of argumentation is to persuade others of the validity of the claim made by the individual or group through well-reasoned or well-grounded arguments. Through dialogical argumentation learners articulate their "reasons for supporting a particular claim and then strive to persuade or convince" others about the truthfulness of such a claim [19]. Dialogical argumentation provides the critical "environment for learners to externalize their doubts, clear their misgivings or misconceptions, reflect on their own ideas and those of their peers in order to arrive at clearer and more robust understanding of a given topic than would have otherwise been the case" [19].

Besides direct instruction and direct questions posed by the teacher, classroom talk can take the form of argumentation. Argumentation in a classroom setting would be mostly between students, if a viewpoint is tabled and justified, or if others demand a justification [29]. This means learners in a science classroom setting need to use the available data to both justify and make sense of a specific claim [40]. To complete the process, warrants and backings are given by the arguers to support the original claim, and rebuttals are given as counter-claims in showing non-compliances to the original claim. The use of argumentation as a way of learning science derives its strength from the nature of (Western) science and the nature of scientific enquiry. Qhobela and Moru [29] see 'scientific knowledge' as a product of intense and robust discussion within the community of scientists. A scientist must convince other members of this community that a finding amounts to a new, acceptable and important contribution to knowledge [11].

Beets and Le Grange [4] argue that in Africa "schools are the sites where most learners first experience the interaction 
between African and Western worldviews". They argue and advocate for the need for teachers working in these contexts to be alert, especially in a South African science teaching context, to "this type of interaction and understand the way it could complicate the learning process" [4]. Much literature has been produced over the years about the experiences of the majority of African and South African learners with learning and understanding science in the classroom. Despite the volume of literature, and the "fact that indigenous knowledge systems reside among the majority of South Africans, the topic has not been given the attention in educational curriculum development policies it deserves, resulting in a lack of attention to indigenous knowledge in the discursive terrains of all learning areas/subjects" [14].

\section{Materials and Methods}

\section{Theoretical Framework}

The study is underpinned by an Argumentation Framework based on Toulmin's [46] Argumentation Pattern (TAP) and Ogunniyi's [23] Contiguity Argumentation Theory (CAT). The two theories accord with Vygotsky's notion of constructivism [39] whereby an individual learns or acquires new experiences from his/her interactions with his/her physical or socio-cultural environment. The TAP construes learning as a "product of self- or cross-conversation and reflection" [31]. This study explores the application of both TAP and CAT in the context of classroom discourse dealing with selected meteorological concepts.

The two theoretical frameworks TAP and CAT were chosen because of their amenability to the investigation of classroom discourse dealing with phenomena about which learners might be holding conflicting worldviews.

\section{TAP and CAT}

In order to participate in a scientific community, students and novices need to know "how to construct substantive arguments to support their" position [46]. Toulmin [46] developed the Toulmin's Argumentation Pattern, a theoretical model that can be used "as a basis for characterizing argumentations in science lessons" [28]. Toulmin [38] also suggested that a substantive argument requires providing supporting data to a claim. In the current research study this model was used to compare and analyse the cognitive understandings of grade 9 learners in terms of their conceptions of selected meteorological concepts.

I would argue that as useful as the Toulmin Argumentation Pattern is in assessing the quality of arguments, subsequent research [19,29] found that it does not address metaphysical IK-rated beliefs that impinge on, or could enrich, learners' understanding of diverse phenomena. It was because of this limitation that Ogunniyi [22] proposed the Contiguity

Argumentation Theory. The effectiveness of argumentation instruction in enhancing learners' understanding of school science is well supported by a plethora of studies $[9,17,18,22,24,25,26]$. In an attempt to mediate between (Western/school) science and IK Ogunniyi [17] proposed the Contiguity Argumentation Theory (CAT) in order to capture learners' experiences which exist beyond the scope of school/Western science. The basis of CAT is that "two distinct co-existing thought systems", such as, in the context of this study, science and IK, "tend to readily couple with, or recall each other to create an optimum cognitive state" Unlike TAP, which only deals with logical substantive arguments [46], CAT "deals with both logical or scientifically valid arguments as well as non-logical metaphysical discourses embraced by IKS" [19].

Teaching methods that use or facilitate argumentation through the use of appropriate activities and teaching strategies in the Social Science class (in Grade 9 Geography in the South African curriculum context) can provide a means of promoting and fulfilling a wider range of educational goals, including social skills, reasoning skills and the skills required to construct argument and knowledge using evidence [26], skills are included under 'Critical Outcomes' in the introduction to the NCS and CAPS. Thus, in advocating that teachers need argumentation during the teaching of Social Science, it needs to be emphasised that they need to adapt their teaching styles from direct instruction/transmission approaches to more dialogic approaches [2] that involve the participation of students in class and lesson discussions, and the use of those teaching methods which include interacting with students in a process of deliberate fostering of students' argumentation skills.

According to Ogunniyi [24,25], the CAT assumes that when different ideas coming from different students interact, they tend (through a sort of dialogical process) to find areas of commonality i.e. areas where their subsumed elements are compatible and may ultimately result in, or metamorphose into, a higher form of meaning than was previously possible [25]. Furthermore Learning Outcome 3 of the Revised National Curriculum Statement Grades R-9 (2002) Science curriculum carries the expectation of learners being able "to demonstrate an understanding of the interrelationship between science and technology, society and the environment" [6]. The same for CAPS (2011) where the Science curriculum "serves a dual purpose: it must enable learners to make sense of the world in scientific terms and prepare learners for continuing with a science(s) into the Further Education and Training (FET) phase ... and beyond" [5]. This outcome serves as an appropriate departure point from which to consider the central concern of the study, namely, grade 9 learners' conceptions of selected meteorological concepts, and their understanding and use of these.

\section{Research Design}

The study is based on a case study design with two main components, namely, a quasi-experimental design with qualitative and quantitative research design components - 
also known as a mixed-method approach. This approach attempts to establish a 'relationship between variables by exercising very tight control over key aspects of the setting in which the research is conducted. In the experimental design form, the approach entails manipulating one variable (known as the independent variable) to observe the effects this has on another variable (the dependent variable).'

In the case of evaluating a teaching strategy, according to Dowling and Brown [9] the "teaching strategy" will act as the "independent variable" and the learners" "scientific reasoning" will be the "dependent variable". As they stand, neither variable is sufficiently well defined, so Dowling and Brown [9] suggest that "in order to construct an experiment, the teaching strategy in which you are interested has to be translated into an explicit procedure, which can be repeated with a high degree of consistency" [9]. This will constitute the experimental treatment of the DAIM-model that will be carried out in the study. According to Ogunniyi [19] the purpose of experimental research is described as "the consequences of a direct intervention into the status quo". This status quo can also be seen as an indicator of the quality of reasoning in order for us to present or render this (scientific reasoning) as visible and measurable in this study.

It is important to remain aware of the fact that the strict demand made by experimental designs can create a number of problems for educational research. In this study, the groups of learners chosen for the study are from a group of grade 9 learners at the research site. Therefore, randomly assigning learners to groups is disruptive and likely, in many if not most circumstances, to be impractical to deal with as a researcher. As the researcher, I am also aware that only with sufficient precision and tightly controlled experimental settings will one be able to apply the prescribed treatment, in this case the DAIM (dialogical argumentation model) without raising concerns about the ecological validity of experimental research in which phenomena are explored in a context other than those in which they naturally occur [9]. This normally happens when groups that have been constructed in this way need to be taken away from the ideal classroom situation to manipulate the treatment they will receive to get the desired results.

Dowling and Brown[9] raise the questions of the typicality of behavior within an experimental context, and the transferability of treatments from an experimental setting to the classroom. The awareness of being part of a research study according to Dowling and Brown [9] might itself influence the research by what is known as the Hawthorne effect. In this case the effects of being researched outweigh the influences of any of the factors being researched. This phenomenon clearly has implications for all forms of observational research. With the experimental research approach there is also potential for ethical problems when it comes to the circumstances in which school children are taught. The experimental researcher should never embark on a journey where the process is harmful to the educational progress of any group of school pupils. Similarly, one must be careful that the research design does not lead to beneficial forms of action being withheld from groups for an extended period of time.

To overcome the possibility that the study could end up producing the Hawthorne effect or encountering other risks to credibility of findings a quasi-experimental type of design was adopted. This design deals with a more complex socio-cultural and economic context that allows for the use of both quantitative and qualitative research methods.

\section{Research Setting}

This research was conducted in a secondary school in what is called a 'previously disadvantaged' community in Cape Town, Western Cape, South Africa. This area formerly hosted the oldest informal community in Western Cape which, in the interests of anonymity, will be referred to as 'Blikkiesdorp' (pseudonym) with a 67 year history dating back to 1948 under the apartheid government in South Africa. With its tin roof and shack-like informal housing structures, it gave permanent residence to more than 750 families in the southern suburbs of the Western Cape. The first primary school of the area was erected as a temporary structure (wooden walls on concrete slabs) adjacent to Blikkiesdorp in the early 1950s. The area and residents are characterized by poverty, and low income and education levels.

\section{Sampling}

This included two intact school class groups from a public high school (school "X" for purposes of anonymity) in the Western Cape. The school is situated in a distinct category of socio-cultural and economic area of ward $801^{*}$ (pseudonym) of the City of Cape Town. The sampling involved two grade 9 classes from the same school. Participants ranged from 14-17 years of age. Classes were positively selected on the basis of comparability with respect to:

- Classes doing the same subject and taught by the same teacher

- Formal class test and reports

- Learners within comparable socio-cultural and economic backgrounds

The two groups were two intact grade 9 classes taught by the same educator who was assigned in the study to teach $\mathrm{C}$ group. The educator was trained in the IKS/Science based approach and was made aware to keep all content close to the meteorological topics as set out in the geography curriculum. The $\mathrm{C}$ group was chosen purposefully after the plan to use a group in another school did not materialize. No doubt, this crisis created an anomalous setting for me and hence constitutes part of the limitations of this study. But as Ogunniyi [19] has argued, research in the social sciences (including education) is fraught with extraneous variables such as history, maturation, high mortality rate, unpredictability of humans who often act and react to contextual changes, lack of universal theories about human behaviours, problems associated with formulating terms or variables with precise operational definitions, etc. Additional limitations were the experience connected to the above $\mathrm{C}$ 
group receiving their intervention before the $\mathrm{E}$ group, meaning that data contamination was possible. This issue was likely resolved by the June school holiday break, over which time most of the learners would have forgotten the intervention.

\section{Quantitative and Qualitative Research Methods}

The qualitative data were derived from learners' written responses in the Conceptions of Weather (CoW), Meteorological Literacy Test (MLT), as well as Classroom Observation Schedules (COS). The quantitative data were derived from learners' performance scores in the Meteorological Literacy Test (MLT).

A teacher on the staff of the school undertook the Comparison (C) group intervention, while I as the researcher took charge of the Experimental (E) group Dialogical Argumentation Instructional Model (DAIM) intervention. The teacher who handled the $(C)$ group used traditional teaching methods, discussions and resources to provide the control component of, and to complete, the research process. The teacher was reminded to use 'normal', accustomed teaching methods according to those specified in the National Curriculum Statement (NCS) [6-8] and the Curriculum Assessment Policy Statement (CAPS) [5,7] that encourage the implementation of IKS into a school Science curriculum as $\mathrm{s} /$ he understood these while I used the Dialogical Argumentation Instructional Model (DAIM) with the experimental (E) group. Both comparison (C) group and experimental (E) groups were exposed to the same Meteorological Literacy Test (MLT) assessment before and after the teaching that happened over a period of eight weeks.

The quantitative aspect of the study was in the form of quasi-experimental (pre-test), case study control group design. The results from the survey and pre-post-test were to be evaluated to interpret the learners' conceptions, and/or the effectiveness/depth of their weather conceptions, as shown below in Figure 1:

\section{Quasi-experimental Control Group Design}

This research design can be both quantitative and qualitative in nature e.g.

$\mathrm{O} 1 \mathrm{X} \quad \mathrm{O} 2$ (Experimental group) $=(\mathrm{E})$

O3 O4 (Control or Comparison Group) $=(\mathrm{C})$

$$
\begin{array}{rrrl}
\mathrm{O} 1 & \mathrm{X} & \mathrm{O} 2 & =\text { Pre-observations } \\
\mathrm{O} 3 & \mathrm{O} 4 & =\text { Post-observations }
\end{array}
$$

Figure 1. Quasi-experimental control group design

\section{The Intervention}

The intervention referred to as (X) focused on the Experimental (E) group only. The intervention was in the form of a CoW (Conceptions of Weather) questionnaire, and based on local indigenous knowledge. The Dialogical Argumentation Instructional Model (DAIM) class room model was used to apply the teaching part of the intervention to the E group. The Control (C) group was used to compare pre-and post test results from the two groups in order to establish whether the intervention applied had been successful.

During the two-month intervention stage the experimental group (E-group) formed four randomized groups. Each group was asked to choose a group leader who would present the outcomes of its discursive arguments on the various tasks to the whole class. It is worth noting that in each session the group had to choose another leader and rotate their individual roles such as reader of the worksheets containing the instructions, recorder, and manipulator of apparatuses or materials. This process was also intended to develop skills other than the understanding and use of meteorological concepts using appropriate resources. For reasons of space limitation further details of the procedures followed in the study which have already been published elsewhere are not repeated here $[16,17,18,22,24,25,34,35,41]$. 


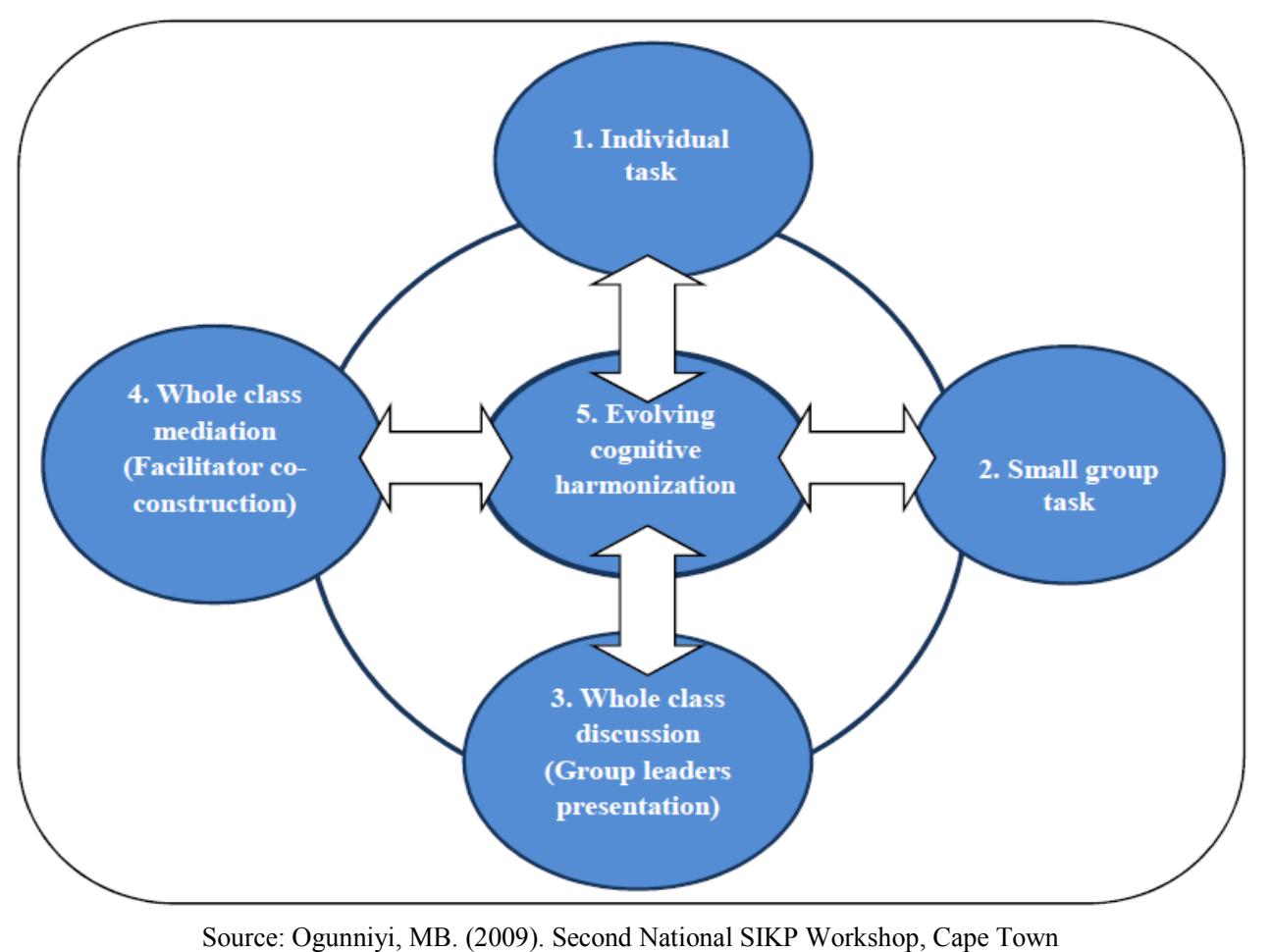

Figure 2. A Pedagogical Scheme for Implementing Dialogical Argumentation Instruction

The author is a member of SIKP (Science Indigenous Knowledge Project) from the School of Science and Mathematics Education at the University of the Western Cape where the above diagram (Figure 2) was generated in order to illustrate the process and trajectory of the DAIM. The 'pedagogical schema' [33] for enacting a dialogical argumentation-based discourse (as shown in Figure 2 above) is a descriptive model arising out of the series of SKIP workshops and has been piloted successfully based on empirical evidence [24,25]. The result of using the pedagogical schema was the attainment of some level of cognitive synchronization on the part of the participants based on convincing evidence and warranting what was recorded during the intervention stage.

\section{Results}

The report of results is to be seen in the context of the original questions and combines the descriptive data with the survey data. Where survey and descriptive data (pre-test) were noted, the CAT was applied to inform and describe the types of findings.

This questionnaire was administered two weeks after the survey questionnaire was completed. The same group that completed the survey completed the CoW questionnaire.

The CoW questionnaire indicated that the learners had little knowledge about IKS and the nature of the impact they have on the local and global community. It appeared that very little indigenous knowledge as such was made use of at home by parents and other family members. If any IKS knowledge was used in daily traditions or practices it was never noted as such by those elders and others as belonging to a cultural system of IK. From this one could assume that it was very difficult or even impossible for learners to be acquainted with the nature and content of cultural knowledge or of IKS when answering the CoW questionnaire.

Much of the traditional/cultural knowledge is derived from elders in our communities. Some of the traditional knowledge has made its way into present day situations through stories and folk-lore passed on through traditional dances, song, rituals and other cultural engagements such as community festivals, weddings, prayer meetings and seminars [40]. According to Jegede[16], prior knowledge is related to the environment and in fact an aspect of it. He further asserts that, the environment could be geographic, domestic or socio-cultural and that, "the two are inseparable with the latter creating and nurturing the former" [14]. A total of 25 subjects from the $\mathrm{E}$ and $\mathrm{C}$ group completed the CoW questionnaire.

Table 1. Non-Parametric 'Like-it' scale overall results of CoW questionnaire

\begin{tabular}{|c|c|c|c|c|c|}
\hline $\begin{array}{c}\text { Nominal } \\
\text { scale }\end{array}$ & $\mathbf{1}$ & $\mathbf{2}$ & $\mathbf{3}$ & $\mathbf{4}$ & \multirow{2}{*}{ Total } \\
\cline { 1 - 5 } $\begin{array}{c}\text { Like-it } \\
\text { Scale }\end{array}$ & $\begin{array}{c}\text { Strongly } \\
\text { Agree }\end{array}$ & Agree & Disagree & $\begin{array}{c}\text { Strongly } \\
\text { disagree }\end{array}$ & \\
\hline $\begin{array}{c}\text { Boys } \\
\text { Beliefs } \\
(\%)\end{array}$ & 15.71 & 40.71 & 34.29 & 9.29 & $=100 \%$ \\
\cline { 1 - 4 } $\begin{array}{c}\text { Girls } \\
\text { Beliefs } \\
(\%)\end{array}$ & 28.57 & 42.15 & 17.14 & 12.14 & $=100 \%$ \\
\hline Total \% & 44.28 & 82.86 & 51.43 & 21.43 & $\begin{array}{c}(200) / 2 \\
=100 \%\end{array}$ \\
\hline
\end{tabular}

In examining the overall results of the conceptions of 
weather (CoW) questionnaire in Table 1 (above) one could conclude that the answers from learners display a more positive and inspired view on the nominal scale $1=$ Strongly Agree $(44.28 \%)$ and nominal scale $2=$ Agree $(82.86 \%)$ then disagree, nominal scale $3=(51.43 \%)$ and nominal scale $4=$ $(21.43 \%)$ respectively on the original questions that were administered to them in the CoW questionnaire. On item 1 'Learning geography through school science is interesting' the collective response count of boys and girls was surprisingly low. Only two boys (8\%) and two girls (8\%) agreed with the statement that they find 'geography interesting'. This claim can be supported by reasons given by learners' as to why they chose to agree or disagree in the following excerpts:

On item 1: some boys (2) responded (direct transcription)

L1: Because there is a lot of stuff to do and to learn about.

L3: Because I don't like it and I don't know what to do when the teacher give the class to me.

Learner L1 is saying that the geography subject has too many complicated sections to deal with, and he shows an awareness of the difficulty of dealing with subject learning material that you do not understand. He also finds it complicated to handle all the various concepts within the geography subject. For L3 being, or having no choice but to be, in the geography classroom and in the presence of other learners, besides his subject teacher, is in itself just too much for him to deal with because he does not like geography as a school subject at all.

The excerpts below are representative of the learner's responses (direct transcription) to certain items in the CoW questionnaire:

On item 1: some girls (2) responded (direct transcription)

L10: The teacher doesn't make it interesting but I make it myself sometimes he makes it interesting.

L12: The children in class makes it not easy to understand the teacher.

No connection between IKS and weather related geography was indicated, although $80 \%$ (16) agree that using IKS to learn geography can help understand the weather better. Out of the 25 participants only 6 , three girls and three boys, responded to their choice of answers.

On Item 2: To 'Using my indigenous knowledge to learn geography helps me to understand weather', some girls (3) responded:

L8: I don't always know what the weather would be.

L9: To know everything about the weather is better than to understand that.

L10: Sometimes I'm wrong but it help a little with geography.

On Item 2, some boys responded:

L15: No, if you don't know geography how can you understand the weather.

L16: Yes, it show all the countries and show the weather.

L18: To know what is going on with the weather.

On Item 4 the girls (2) responses were:

L18: It's not the same every time.

\section{L10: I don't believe in both.}

On Item 4 boys (3) responses were:

L16: It shows on the news what is the weather going to be.

L18: Their knowledge is better than ours.

L20: Because indigenous knowledge will not show you about the weather.

\section{Findings on CoW}

Among other responses, the excerpts above suggest that most learners have never been exposed to IKS in the field of Geography, and that for them there is no connection or relation between IKS and their understandings of weather phenomena.

Not all learners completed the response section, and this resulted in less than half of the total questionnaires that were administered being fully completed. This also demonstrated that the learners did not show interest in reading and making time to answer questions properly. The lack of interest shown in many of the partially completed questionnaires leads to the impression that most of the learners are either not interested in Geography as a subject, or the teaching of the subject is poor or uninteresting or ineffective, particularly in terms of the impact it has on their daily lives.

From the responses of the Grade 9 learners to the CoW questionnaire one can conclude that Geography is not a favourite subject at their school, possibly mainly due to the lack of resources both at their school and from the DoBE (Department of Basic Education). Most of the learners' current knowledge on weather and the environment seemed to be derived from school/Western knowledge, with very little knowledge gleaned from an indigenous knowledge perspective. In fact some learners had never heard of IKS. Some even mentioned that they had never encountered the term IKS. From this I would argue that teaching strategies should be initiated, and resources provided or acquired, that showcase the importance of tapping into indigenous knowledge for easier and more relevant acquisition and use of geography concepts by learners, and concepts which are of value to them both in the classroom and in their everyday lives.

\section{DAIM Findings}

DAIM findings which emerged from analyzing both the quantitative and qualitative data and are as follows:

- E group learners being exposed to argumentation in the classroom during the DAIM intervention process seemed to have enhanced their awareness of the Nature of Science (NOS) and the Nature of IKS more than those in the $\mathrm{C}$ group who were not exposed to this learning strategy.

- E and C groups held relatively good conceptions of weather processes. Their attitudes as revealed in the questionnaire indicated that both groups possessed valid scientific conceptions about weather and meteorological science. 
Both groups' pre-test responses to the attitudes questionnaire based on the framework of the Contiguity Argumentation Theory (CAT) revealed that they held largely equipollent views (i.e. Scientific and IKS-based) of weather (Geography). This suggests that they held both the Western scientific and the IKS-based views of weather knowledge in a co-existing manner.

Learners that were exposed to the DAIM intervention developed a better understanding and attitude towards a science worldview, and value the use of IK embedded science lessons.

The Experimental (E) group learners appeared to have developed a positive attitude and better understanding towards science and an enhanced awareness of the Nature of Science (NOS) and the Nature of IKS (NOIKS), when compared to the Control (C) group.

Table 2. EXPERIMENTAL \& CONTROL GROUP - Pre-post -test scores compared

\begin{tabular}{|c|c|c|c|}
\hline $\begin{array}{c}\text { E } \\
\text { GROUP }\end{array}$ & PRE-TEST & POST-TEST & $\begin{array}{c}\text { PRE \& } \\
\text { POST DIFF }\end{array}$ \\
\hline MEAN & 18.88 & 29.87 & 10.87 \\
\hline SD & 3.31 & 4.28 & 3.75 \\
\hline \multicolumn{4}{|c|}{ t-TEST: $\mathrm{N}=15$, Critical t-value $=2.131$, Alpha $=0.05$} \\
\hline $\begin{array}{c}\mathrm{C} \\
\text { GROUP }\end{array}$ & PRE-TEST & POST-TEST & $\begin{array}{c}\text { PRE \& } \\
\text { POST DIFF }\end{array}$ \\
\hline MEAN & 14.33 & 15.45 & 1.36 \\
\hline SD & 4.39 & 3.72 & 6.34 \\
\hline \multicolumn{4}{|c|}{ t-TEST: $\mathrm{N}=10$, Critical t-value $=2.201$, Alpha $=0.05$} \\
\hline
\end{tabular}

Both groups were exposed to the conceptions of weather science and IKS content test, the Meteorological Literacy Test (MLT), and the average scores were almost the same for both groups in the pre-test. The E group had an average of $18.88(37.76 \%)$ and the $\mathrm{C}$ group had an average of 14.33 $(28.67 \%)$, as indicated in Table 2 above. The mean results of the E group had significantly improved from an 18.88 mean to a 29.87 mean, with an overall 10.87 mean value improvement after the IKS and DAIM intervention. On the other hand the $\mathrm{C}$ group scored a 14.33 mean value in the pre-test and a 15.45 mean value in the post-test, with a mere 1.36 overall mean value improvement with no intervention exposure. Thus a significant improvement of 10.87 in the overall mean results in the E group as opposed to the 1.36 mean values in the $\mathrm{C}$ group can be noted. I argue that this difference in mean value score improvements between the two groups can be attributed to the DAIM intervention that was applied only to the E group and not to the $\mathrm{C}$ group. Both groups completed the MTL in the pre-post test.

\section{Conclusions}

When learners at "X" Secondary School were exposed to a Science and IKS-based conceptions of meteorological concepts, both study groups' mean scores were above a $50 \%$ of the total marks expected. This indicated that, even though the learners had not been exposed to prior meteorological concepts, they had their own existing conceptions. This finding is also in line with the CAPS policy statement, [6] which asserts that even adults have different ways of thinking for different situations. As Ogunniyi [17] has argued, learners in Natural Sciences Learning area think in terms of more than one worldview. According to Le Grange [25] learners do possess knowledge that could potentially be 'lost' if not properly harnessed. The question which is begging for an answer is, which of this 'lost' knowledge is valid or invalid and hence worth consideration [11]. The challenge posed by these diverse views is that they are underpinned by different epistemic, ontological and axiological beliefs. Some attempts have been made to change learners' indigenous conceptions of various natural phenomena to the scientific worldview [33] but these have not resulted in much success. Based on their review of the extant literature in the area, Gunstone and White [14] have come to the conclusion that:

The issue now appears to be not of abandonment and the replacement, but one of addition, so that the earlier belief and scientific belief co-exist. The learner's task is to learn the scientific belief, and to become clear about when it is appropriate to apply one belief or the other (p.298).

In support of the view Ogunsola-Bandele [31] has stated that science and IKS should be allowed to co-exist. Some studies concerned with blending formal and informal knowledges have come to the conclusion that it is possible to blend formal science and informal science. However, Finley has asked another probing question relating the co-existence of the two worldview systems, that is, "how could we tell when the intersections are productive and when they are valid or not?" [11]. In the light of the questions asked by Finley, Onwu [32] relating to the issue of which aspects of IKS are to be incorporated in the school curriculum as well as Gunstone and White's conclusions based on the extant literature, Ogunsola-Bandele, has added that, "African science educators have the challenge of searching and providing scientific explanations for traditional African culture, beliefs and superstitions" (p. 56). I concur with Ogunsola- Bandele, because if areas of commonalities can be identified, there might no longer be any concerns about the quality of a Science and IKS-based curriculum. In conclusion, the assertion of the finding that, learners held 'valid' or relatively good conceptions of indigenous weather prediction were based on the questionnaire which was designed and structured in such a way that it was possible to extract 'scientifically valid' conceptions of indigenous weather prediction from the learners' pre-test responses.

I would argue that the Dialogical Argumentation Instructional Model (DAIM) provides an alternative lens for explaining many of the empirical findings in science/IKS education. DAIM also addresses the shortcomings of alternative frameworks for scientific reasoning. DAIM can also be used and taught as a model for the reasoning processes of science. 


\section{REFERENCES}

[1] Aikenhead, G.S. (1996). Science Education: Border crossing into the subculture of science. Studies in Science Education, $27,1-52$.

[2] Alexander, R. (2005). Towards dialogic teaching. York, UK: Dialogos.

[3] Amosun, I.O., Ogunniyi, M.B. \& Riffel, A.D. (2013). Conceptual attitudinal and practical change concerning science indigenous integration using argumentation. Proceedings of the 19th Annual Meeting of the Southern African Association for Research in Mathematics, Science and Technology Education (pp. 348-362). Bellville, Cape Town: University of the Western Cape.

[4] Beets, P. \& Le Grange, L. (2005). Africanising assessment practices: Does the notion of ubuntu hold any promise? South African Journal of Higher Education, 1197-1207.

[5] Department of Education . (2011). Curriculum Assessment Policy Statement, CAPS. Basic Education, Education. Pretoria: Department of Basic Education, Government Printers.

[6] Department of Education. (2002). C2005: Revised National Curriculum Statement R-9 (schools) Policy for the Natural Science. Pretoria: Department of Basic Education Government Printer.

[7] Department of Education. (2013). 2013 - National Senior Certificate Examination: School Subject Report. Department of Basic Education. Pretoria: Department of Basic Education: Government Printing.

[8] Department of Education. (2013, December 6). Media Release. National Senior Certificate Results of 2013. Retrieved January 7, 2014, from Western Cape Education Department: http://wced.gov.za

[9] Dowling, P., \& Brown, A. (2010). Doing research/ reading research: re-interrogating education. New York: Routledge

[10] Erduran, S.; Simon, S., \& Osborne, J. (2004). TAPing into argumentation: Developments in the application of Toulmin's argumentation pattern for studying science discourses. Science Education, 88, 915-933.

[11] Finley, F. (2009). Indigenous Environmental Knowledge: A source for science curriculum from Thailand. Second National Workshop on Science and IKS, page 51 - 53 . University of the Western Cape, RSA.

[12] Fleer, M. (1997). Science, technology and culture: Supporting multiple world views in curriculum design. Australian Science Journal, 43, 13-18.

[13] Ford, M.J., \& Forman, E.A. (2006). Redefining disciplinary learning in classroom context. In J, Green, A. Luke \& G. Kelly (Eds.), Review of Educational Research (Vol. 30, pp. 1-31). Washington, DC: American Education Research Association.

[14] Gunstone, R. and White, R. (2000). Goals, methods and achievements of research in science education. In R. Millar, J. Leach and J. Osborne (eds) Improving science education: The contribution of research. pp. 293-307. Buckingham: Open University Press

[15] Goodenough, K. (2001). Multiple Intellegences Theory: A framework for personalising science curricula. School Science and Mathematics, 101, 180-192.

[16] Jegede, O.J., \& Aikenhead, G.S. (1999). Transcending Cultural Borders: Implications for science teaching. Research in Science \& Technological Education, 17(1), 45-66.

[17] Jegede, O.J. (1996). Fostering Students' Understanding of Science Concepts. A special Keynote paper for the 37 Annual Conference of the Science Teachers' Association of Nigeria,Uyo, Akwam Ibom State, 12 - 17 August 1996

[18] Le Grange, L. (2007). Integrating Western and Indigenous Knowledge Systems: The basis for effective science education in South Africa. International Review of Education, $53,577-591$.

[19] Le Grange, L. (2004). ). 'Multicultural'Science in South Africa's National Curriculum Statement, Africa Education Review, 1(2), 204 - 219.

[20] Linkson, M. (1997). Some issues in providing cultural appropriate science curriculum support for indigenous learners. Australian Science Journal, 45, 41-49.

[21] Ogunniyi, M. (1992). Understanding research in the social science. Ibadan: University Press Plc.

[22] Ogunniyi, M. (2007a). Teachers' Stances and Practical Argumentation Regarding a Science-Indigenous Knowledge Curriculum: Part 1. International Journal of Science Education, 29(8), 963-986.

[23] Ogunniyi, M. (2007b). Teachers' Stances and Practical Argumentation Regarding a Science-Indigenous Knowledge Curriculum: Part 1. International Journal of Science Education, 29(10), 1189-1027.

[24] Ogunniyi, M.B \& Hewson, M.G. (2008). Effects of an Argumentation-Based Course on Teachers' Disposition towards a Science-Indigenous Knowledge Curriculum. International Journal of Environmental \& Science Education, 3(4), 159-177.

[25] Ogunniyi, M.B. (1987). Conceptions of traditional cosmological ideas among literate and non -literate Nigerians. Journal of Research in Science Teaching, 24(2), 107-118.

[26] Ogunniyi, M.B. (2002). "Border crossing and the contiguity learning hipothesis" (Unpublished paper delivered at the). 10th Annual Meeting of the Southern African Association for Research in Mathematics, Science and Technology Education.

[27] Ogunniyi, M.B. (2004). The challenges of preparing and equipping science teachers in higher education to integrate scientific and indigenous knowledge systems for subjects. South African Journal of Higher Education, 18(3), 239-304.

[28] Ogunniyi, M.B. (1997). Curriculum 2005: A Panacea or a Pandora's Box? (Vol. Seminar series 1). Bellville: Published by the School of Science and Mathematics Education at the University of the Western Cape.

[29] Ogunniyi, M.B. (2011a). Exploring science educators cosmological worldviews through the binoculars of an argumentation framework. South African Journal of Higher Education, 25(3), 542-542. 
[30] Ogunniyi, M.B. (2011b). The context of training teachers to implement a socially relevant science education in Africa. African Journal of Research in Mathematics, Science and Technology Education, 15(3), 98-121.

[31] Ogunsola-Bandele, M. F. (2009). Blending science with indigenous knowledge to enhance learners' understanding of natural phenomena. Second Nation Workshop on Science and Indigenous knowledge Systems, $29^{\text {th }}-31^{\text {st }}$ October 2009. University of the Western Cape.

[32] Onwu, G. (2009). Introducing IKS into the science curriculum: What develops? An exercise with in-service student teachers. Second National Workshop on Science and IKS, page 21 - 27. University of the Western Cape, RSA.

[33] Osborne, J.; Erduran, S. \& Simon, S. (2004a). Enhanching the quality of argument in school science. Journal of Research in Science Teaching, 41(10), 994-1020.

[34] Peacock, A. (1995). Access to science learning for children in rural Africa. International Journal of Science Education, 17, $149-166$

[35] Pedemonte, B. (2007). How can the relationship between argumentation and proof be analysed. Educational Studies in Mathematics, 66(1), 23-41.

[36] Posner, G. J., Stirke, K. A., Hewson, P. W., and Gertzog, W. A. (1982). Accommodation of a scientific conception: Towards a theory of conceptual change. Science Education, Vol. 66, No.2,pp. 211-227

[37] Qhobel, M., \& Moru, E.K. (2011). Learning physics through argumentation at secondary school level in Lesotho: A feasible teaching strategy? African Journal of Research in Mathematics, Science and Technology Education, 15(2), 205-219.

[38] Riffel, A.D. (2011). What effect will dialogical argumentation have on a grade 9 learners conceptual understanding of selected meteorological concepts when used as an instructional method in a science classroom in the Western Cape, South Africa. Proceedings of the 19th Annual Meeting of the Southern African Association for Research in Mathematics, Science and Technology Education (pp. 121-128). Mafikeng, South Africa: North-West University.

[39] Riffel, A.D. (2014). Effects of a Conceptions of Weather (CoW) questionnaire on grade 9 learners beliefs on
Indigenous Knowledge: Using dialogical argumentation as an instructional tool. 22nd Annual Conference of the Southern African Association for Research in Mathematics, Science and Technology Education (p. 276). Port Elizabeth \& George: Nelson Mandela Metropolitan University (NMMU), Routledge.

[40] Riffel, A.D. (2013). The Role of Indigenous Knowledge Systems in enhanching grade 9 learners' understanding of a Natural Science Education Curriculum: A survey in a Geography classroom in Cape Town, South Africa. Proceedings of the 21 st Annual Meeting of the Southern African Association for Research in Mathematics, Science and Technology Education (pp. 500-512). Bellville, Cape Town: University of the Western Cape.

[41] Siseho, S. (2013). The Effect of an Argumentation Instructional Model on Pre-Service Teachers' Ability to Implement a Science-IK Curriculum (Doctoral Thesis). Department of Education. Bellville, Cape Town: University of the Western Cape.

[42] Siseho, S.C \& Ogunniyi, M.B. (2011). A critical analysis of classroom discourse and co-construction of knowledge relative to the preparation and production of an African staple food. Book of proceedings of the Southern African Association for Research in Mathematics, Science and Technology Education (pp. 490-502). Mafikeng, South Africa: Department of Education, North West University.

[43] Siseho, S.C. \& Ogunniyi, M.B. (2010). Using an Argumentation-Based Instructional Model to enhance Teachers' Ability to Co-construct Scientific Concepts. Book of proceedings of the Southern African Association for Research in Mathematics, Science and Technology Education (pp. 19-23). Pinetown, South Africa: Department of Education, University of KwaZulu Natal, .

[44] Stears, M. \& Malcom, C. (2005). Learners and teachers as co-designers of relevant science curricula. Perspectives in Education, 23(3), 21-30.

[45] Terwel, J. (1999). Constructivism and its implications for curriculum theory and practice. Journal of Curriculum Studies, 31, 195-199.

[46] Toulmin, S. (1985). The uses of argument. Cambridge, UK: Cambridge University Press.

[47] Vygotsky, L.S. (1978). Mind and Society. Cambridge, MA: Harward University Press. 